\title{
EVALUATION OF A SYSTEMATIC APPROACH TO MATRIX ACIDIZING ON AN OIL PRODUCING WELL
}

\author{
Okologume C. Wilfred ${ }^{1}$, Marcus Bourdelon Umeleuma ${ }^{2}$ \\ ${ }^{1}$ Graduate Assistant, Department of Petroleum and Natural Gas Engineering, Federal University of Petroleum \\ Resources, Effurun, Delta State, Nigeria \\ ${ }^{2}$ Graduate Student, Department of Petroleum and Gas Engineering, University of Port Harcourt, Rivers State, \\ Nigeria
}

\begin{abstract}
All wells are susceptible to formation damage to some degree, ranging from relatively minor loss of productivity to plugging of specific zones. Formation damage could simply be referred to as a term used to emphasize reduced current production. Acidizing is a well stimulate technique where acids are primarily used to remove or cure damage around wellbore caused by drilling, completion, production and work over operations in order to improve production. In matrix acidizing, acid is used to remove the damage near the wellbore. This removal of severe plugging in sandstone, limestone or dolomite by matrix acidizing process can lead to large increase in well productivity. It is expected that matrix acid treatment should remove flow restrictions near the wellbore and allow the well to produce at an undamaged rate. However, the production rate after treatment is sometimes lower than predicted or in extreme cases without any improvement at all. This study evaluates matrix acidizing operations in oil producing wells with a view to identifying causes of acidizing failures and developed a systematic approach to matrix acidizing that will eliminate failures and greatly enhance the performance of acidized oil wells. Discussions have been centered on the fundamentals of formation damage and acidizing, review of existing literature on the subject and matrix models. In treated wells studied, stimulation ratios from productivity indices were almost equal to or greater than $2(\geq 2)$ and always greater than stimulations ratios from production rates, showing that the treatments were positive in reducing or curing damage around the wellbore but the stimulation ratios from the two parameters (productivity index and production rate) were not the same as a result of flow restrictions. Since all treated intervals in the different wells studied showed positive response to damage reduction, it could be concluded that acidizing if properly executed will reduce or cure damage around the wellbore and improve productivity.
\end{abstract}

Key Words: formation damage, matrix acidizing, stimulation, and productivity, stimulation ratio, etc...

\section{GENERAL OVERVIEW}

In order to maximize oil production, operators can either drill new wells or stimulate existing ones. To drill a new well involves considerable expense, and a time period ranging from weeks to months [9]. On the other hand, a stimulation treatment is only a fraction of the cost of a new well and it can be stimulated within one or two days. Increasing production by stimulation is achieved by either hydraulic fracturing or matrix acidizing. If a well is not producing as expected, the formation might have been damaged, thus resulting to a reduced rate of production.

This damage may be due to minor or complete plugging of specific zones. These obstructions prevent the well from flowing properly. When a well is damaged, the permeability of the reservoir rocks in the damaged zone is reduced [6]. Permeability explains the ability of the reservoir rocks to conduct fluids. Consequently, a reduction in permeability will invariably result in reduction in production rate. A number of other factors lead to a reduced production rate usually experienced in practice. Such factors include: high fluid viscosity, reduced porosity, a high value of skin, failure of equipment etc. [10]. These factors could be taken care of in different ways. High fluid viscosity means high resistance to flow, thus leading to low rate in reservoirs. This problem could be taken care of by application of thermal stimulation method (i.e. raising the fluid temperature), which may be by steam soaking. The problem of reduced porosity could be improved by hydraulic fracturing techniques [5]. And equipment failure by effecting repairs as well as replacement of completely damaged ones.

However, if the reduction in production is as a result of skin damage, it becomes necessary to acidize in order to cure or remove damage around the wellbore to improve production. Acidizing could be defined as a stimulation method where acids are primarily used to remove or cure damage around the wellbore caused by drilling, completion, work over, and production operations in order to improve production of oil and gas [2].

It is expected that matrix acid treatment should remove flow restrictions near the well bore and allow the well to produce at an undamaged rate. However, the production rate after treatment is sometimes lower than predicted or in extreme cases without any improvement at all. This occurs due to flow restrictions after treatment which occurs most often as a result of precipitation of acid reaction products [6], a change in the wettability of the rock from water wet to oil 
wet, the formation of emulsion between the reacted acid and formation oil resulting from a poorly executed matrix acidizing job [1].

The objective of this study is to evaluate matrix acidizing operations in oil producing wells with a view to identifying causes of acidizing failures and developing a systematic approach to matrix acidizing that will eliminate failures and greatly enhance the performance of acidized oil wells as a result of quality job execution.

\subsection{Effective Matrix Acidizing}

For matrix acidizing job on an oil producing well to be classified as effective, it must basically increase production rates of the candidate well.

As earlier defined, acidizing is a well stimulate technique where acids are primarily used to remove or cure damage around wellbore caused by drilling, completion, production and work over operations in order to improve production. In matrix acidizing, acid is used to remove the damage near the wellbore in almost all types of wells. This removal of severe plugging in sand stone, limestone or dolomite by matrix acidizing process can lead or result in large increase in well productivity [8].

Emphasis would be centered on methods of acidizing, Acid types used and common well problems associated with acidizing operations.

\subsection{Methods of Acidizing}

There are two major acidizing methods applicable to curing damage around the well bore. These methods are namely:

1. Matrix Acidizing and

2. Acid fracturing

Note that a third method known as "Acid washing" also exists [3]. These two basic methods are characterized by injection rates and pressure is termed "Matrix Acidizing".

Matrix acidizing can be applied to both carbonate and sandstone formations while fracture acidizing has application only to carbonate formations. Fracture acidizing is an alternative to hydraulic fracturing and propping in carbonate reservoirs. Here, the reservoir is hydraulically fractured and then the fracture faces are etched with acid to provide linear flow channels to the wellbore. Problems associated with this method include fracture closure after etching relatively homogenous carbonates and plugging of the fracture if appreciable quantities of un-dissolved fines are released by the acid [4].

\subsubsection{Parameters For Acidizing Job Evaluation}

The following parameters are useful in the evaluation of acidizing jobs which are said to be effective. These parameters include:

\section{(a) Productivity Index (PI)}

This is defined as the ratio of the producing rate of a well to its pressure drawdown at that particular rate. This is expressed mathematically as;

$P I=\frac{Q}{P_{s}-P_{w f}}$

Where:

$\mathrm{Q}=$ Rate of production, (bbl/day)
$\mathrm{P}_{\mathrm{S}}=$ Static bottom hole pressure (psi)

$\mathrm{P}_{\mathrm{wf}}=$ Flowing bottom hole pressure $(\mathrm{psi})$

(b) Flow Efficiency (FE)

This refers to the ratio of actual productivity index of a well to its productivity index if there was no skin (i.e $S=0$ )

Mathematically,

$$
\begin{aligned}
& F E=\frac{P I_{\text {actual }}}{P I_{\text {ideal }}} \\
& P I_{\text {actual }}=\frac{Q}{P_{S}-P_{w f}} \\
& P I_{\text {ideal }}=\frac{Q}{P_{S}-P_{w f}-D P_{\text {skin }}}
\end{aligned}
$$

Therefore, substituting equations (3) and (4) into (2), we have,

$$
F E=\frac{P_{S}-P_{w f}-D P_{S k i n}}{P_{S}-P_{w f}}
$$

Where:

$\mathrm{DP}_{\text {skin }}=$ pressure drop due to skin, $(\mathrm{psi})$

FE gives an idea of how effective or how efficient the completion method is. It can also be called productivity ratio, the condition ratio or completion factor.

(c) Damage Ratio (DR)

This is the ratio of the difference between undamaged and damaged rates of production to the undamaged rate. The damaged ration (DR) is given by the expression:

$$
D R=\frac{\left(Q_{0}-Q_{d}\right)}{Q_{0}}
$$

Where

$\mathrm{Q}_{\mathrm{o}}=$ undamaged production rate, ( bbl/day)

$\mathrm{Q}_{\mathrm{d}}=$ damaged production rate, ( bbl/ day)

(d) Damage Factor (DF)

The difference between unity and the flow efficiency (FE), and it is described as the damage factor. It gives an idea of the extent of damage of a well. This is expressed mathematically as;

$\mathrm{DF}=1-\mathrm{EF}$

\subsubsection{Well Problems Associated With Matrix Acidizing}

The use of acids in well stimulated can create a number of problems some of which include:

i. Release of fines that could plug the formation

ii. Formation of precipitates

iii. Formation of emulsions

iv. Creation of sludge

v. Corrosion of steal etc.

Acid additives could be used as a precautionary or corrective measure to the well problem outlined above. Acid additives normally used in practice include:

$\begin{aligned} \text { i. } & \text { Anti sludge agents } \\ \text { ii. } & \text { Corrosion inhibitors } \\ \text { iii. } & \text { Sequestering agents } \\ \text { iv. } & \text { Fluid loss control agents } \\ \text { v. } & \text { Diverting of bridging agents } \\ \text { vi. } & \text { Surfactants etc. }\end{aligned}$




\section{RESEARCH METHODOLOGY}

A purely analytical approach was adopted as the method of study in this research work. Oil producing wells which have been acidized was used for this study in other to evaluate matrix acidizing generally with the view of identifying problems of matrix acidizing that cause failures, so as to propose appropriate effective measures for such scenarios. The well performance data for acidized wells in this study was obtained from the flow station report issued by the production technology department of one of the producing oil companies operating in the Niger Delta.

An outline of the research methodology is as follows:

i The most appropriate mathematical model was used were necessary to diagnose damage and evaluate the acidizing process.

ii Appropriate mathematical models was also used in evaluation of oil producing wells with acidizing experience.

\subsection{Data Analysis Technique}

The success of any acid treatment is evaluated in terms of achieving initial oil gain and subsequently sustaining this gain over a period of time. In this research work, mathematical models and graphical method was used to analyze well performance data for the candidate wells after acidizing operations have been carried out.

\subsubsection{Models for the Analysis of Field Data}

The following models are useful in the analysis of field data for proper job evaluation:

(A) PERCENT REDUCTION IN SKIN (\% SR)

In determining how successful a treatment is in eliminating or curing damage around the wellbore, the pre-job skin (S1) and the post job skin (S2) values are determined from the pre-job and post job bottomhole pressure survey (BHPS) respectively from which the percentage reduction in skin could be calculated using the mathematical relationship below:

$\% S R=\left(\frac{S_{1}-S_{2}}{S_{1}}\right) \times 100$

Where,

$\mathrm{S}_{1}=$ pre-job skin value

$\mathrm{S}_{2}=$ post job skin value

(B) STIMULATION RATIO

This is the ratio of the post job productivity index to that of the pre-job. However, in the absence of BHP survey data, the ratio of the post-job rate to the pre-job rate could be used in determining the stimulation ratio. The stimulation ratio obtained from production rates may not necessarily represent the actual stimulation ratio due to flow restrictions not necessarily resulting from failure of job but mechanical constraints. Consequently, the ratio of the post-job productivity index to the pre-job productivity index is a better alternative in evaluating the success of the stimulation treatment. Generally, stimulation ratios greater than or equal to two (2) represent a good stimulation treatment. Mathematically:

Stimulation Ratio $($ From PI $)=\mathrm{P} 1_{2} / \mathrm{P} 1_{1}$
$\mathrm{PI}_{1}$ Productivity index before execution of job $\mathrm{PI}_{2}=$ Productivity index after execution of job. Also;

Stimulation Ratio (From Flow Rates) $=\mathrm{Q}_{2} / \mathrm{Q}_{1}$

Where,

$\mathrm{Q}_{1}=$ pre-job production rate (assumed to be the last rate before execution of job).

$\mathrm{Q}_{2}=$ Post job production rate (assumed to be the first after execution of job).

(C) STIMULATION GAIN

The difference between the post-job rate and the pre-job rate is the tested stimulation gain in production. Here, the test rate for the month before the job was executed is considered as the pre-job rate $(\mathrm{Q} 1)$, while the first test rate usually the first month after job execution is used as the post-job rate $\left(\mathrm{Q}_{2}\right)$. Mathematically,

Stimulation Gain $=\mathrm{Q}_{2}-\mathrm{Q} 1$.

In cases where applying equation 11 gives a negative value, the gain is assumed to be zero (0). This means that there was no gain in production rate immediately after stimulation. However, gain in production may be experienced some months later especially in eases where the wells were still cleaning up the month after the job and values obtained were used in calculating the tested stimulation gain. Also, gain might be obtained if the well is subsequently beaned up.

\subsection{Presentation of Field Data \\ WELL NAME: A}

FORMATION TYPE: SANDSTONE

DATE OF STIMULATION: JULY 2012.

Table 1a: Flow History for Well A

\begin{tabular}{|l|l|l|l|}
\hline STAGE & NET RATE $(\mathbf{b b l} / \mathbf{d})$ & PI $(\mathbf{b b l} / \mathbf{d} / \mathbf{p s i})$ & SKIN \\
\hline Pre Job & 1489 & 3.00 & 200 \\
\hline Post Job & 1420 & 5.40 & 68 \\
\hline
\end{tabular}

Table 1b: WELL PERFORMANCE DATA FOR WELL A (APRIL 2012 - FEBRUARY 2013)

\begin{tabular}{|l|l|l|}
\hline DATE & BEAN SIZE & NET RATE (bbl/d) \\
\hline APRIL 2013 & 20 & 1480 \\
\hline MAY 2013 & 20 & 1464 \\
\hline JUNE 2013 & 20 & 1489 \\
\hline JULY 2013 & 20 & 1453 \\
\hline AUG 2013 & 20 & 1420 \\
\hline SEPT 2013 & 20 & 1435 \\
\hline OCT 2013 & 20 & 1476 \\
\hline NOV 2013 & 20 & 1461 \\
\hline DEC 2013 & 24 & 1951 \\
\hline JAN 2014 & 24 & 1952 \\
\hline FEB 2014 & 24 & 2003 \\
\hline
\end{tabular}

WELL NAME: B

FORMATION TYPE: SANDSTONE

DATE OF STIMULATION: FEBRUARY, 2013.

Table 2a: Flow History for Well B

\begin{tabular}{|l|l|l|l|}
\hline STAGE & NET RATE (bbl/d) & PI (bbl/d/psi) & SKIN \\
\hline Pre Job & 430 & 1.50 & 83.25 \\
\hline Post Job & 333 & 2.44 & 36.04 \\
\hline
\end{tabular}


Table 2b: WELL PERFORMANCE DATA FOR WELL A (NOVEMBER 2012 - MARCH 2014)

\begin{tabular}{|l|l|l|}
\hline DATE & BEAN SIZE & NET RATE (bbl/d) \\
\hline NOV 2012 & 16 & 514 \\
\hline DEC 2012 & 16 & 496 \\
\hline JAN 2013 & 16 & 430 \\
\hline FEB 2013 & 16 & 434 \\
\hline MAR 2013 & 16 & 333 \\
\hline APR 2013 & 16 & 339 \\
\hline MAY 2013 & 21 & 725 \\
\hline JUNE 2013 & 24 & 1054 \\
\hline JULY 2013 & 24 & 1461 \\
\hline AUG 2013 & 24 & 601 \\
\hline SEPT 2013 & 24 & 594 \\
\hline OCT 2013 & 24 & 555 \\
\hline NOV 2013 & 24 & 569 \\
\hline DEC 2013 & 24 & 659 \\
\hline JAN 2014 & 24 & 670 \\
\hline FEB 2014 & 24 & 680 \\
\hline
\end{tabular}

WELL NAME: C

FORMATION TYPE: SANDSTONE

DATE OF STIMULATION: MAY, 2014.

Table 3a: Flow History for Well C

\begin{tabular}{|l|l|l|l|}
\hline STAGE & NET RATE $(\mathbf{b b l} / \mathbf{d})$ & $\begin{array}{l}\text { PI } \\
(\mathbf{b b l} / \mathbf{d} / \mathbf{p s i})\end{array}$ & SKIN \\
\hline PRE JOB & 538 & 2.32 & 14.04 \\
\hline POST JOB & 925 & 8.81 & 0.3 \\
\hline
\end{tabular}

Table 3b: WELL PERFORMANCE DATA FOR WELL C (JUNE 2013 - SEPTEMBER 2014)

\begin{tabular}{|l|l|l|}
\hline DATE & BEAN SIZE & NET RATE (bbl/d) \\
\hline JUNE 2013 & 20 & 577 \\
\hline JULY 2013 & 20 & 644 \\
\hline AUG 2013 & 20 & 419 \\
\hline SEPT 2013 & 20 & 538 \\
\hline MAY 2014 & 20 & 587 \\
\hline JULY 2014 & 20 & 880 \\
\hline AUG 2014 & 20 & 925 \\
\hline SEPT 2014 & 20 & 925 \\
\hline
\end{tabular}

WELL NAME: D

FORMATION TYPE: SANDSTONE

DATE OF STIMULATION: MAY, 2013.

Table 4a: Flow History for Well D

\begin{tabular}{|l|l|l|l|}
\hline STAGE & $\begin{array}{l}\text { NET RATE } \\
(\mathbf{b b l} / \mathbf{d})\end{array}$ & $\begin{array}{l}\text { PI } \\
(\mathbf{b b l} / \mathbf{d} / \mathbf{p s i})\end{array}$ & SKIN \\
\hline PRE JOB & 337 & 2.7 & 136 \\
\hline POST JOB & 422 & 7.8 & 27.88 \\
\hline
\end{tabular}

Table 4b: WELL PERFORMANCE DATA FOR WELL D (AUGUST 2012 - MARCH 2014)

\begin{tabular}{|l|l|l|}
\hline DATE & BEAN SIZE & NET RATE (bbl/d) \\
\hline AUG 2012 & 12 & 548 \\
\hline NOV 2012 & 12 & 787 \\
\hline APR 2013 & 18 & 337 \\
\hline AUG 2013 & 24 & 422 \\
\hline NOV 2013 & 24 & 468 \\
\hline MAR 2014 & 30 & 473 \\
\hline
\end{tabular}

WELL NAME: E

FORMATION TYPE: SANDSTONE

DATE OF STIMULATION: APRIL, 2013.

Table 5a: Flow History for Well E

\begin{tabular}{|c|c|c|c|}
\hline STAGE & $\begin{array}{l}\text { NET } \\
(\text { bbl/d) }\end{array}$ & PI (bbl/d/psi) & SKIN \\
\hline PRE JOB & 2000 & 5.7 & 117 \\
\hline POST JOB & 3713 & 29.2 & -3 \\
\hline
\end{tabular}

Table 5b: WELL PERFORMANCE DATA FOR WELL E (DECEMBER 2012 - MARCH 2014)

\begin{tabular}{|l|l|l|}
\hline DATE & BEAN SIZE & NET RATE (bbl/d) \\
\hline DEC 2012 & 52 & 3400 \\
\hline JAN 2013 & 52 & 3400 \\
\hline FEB 2013 & 52 & 2000 \\
\hline APR 2013 & 52 & 3406 \\
\hline AUG 2013 & 52 & 3713 \\
\hline SEPT 2013 & 52 & 3713 \\
\hline NOV 2013 & 52 & 3713 \\
\hline JAN 2014 & 52 & 3714 \\
\hline FEB 2014 & 52 & 3718 \\
\hline MAR 2014 & 52 & 3718 \\
\hline
\end{tabular}

2.4 Results

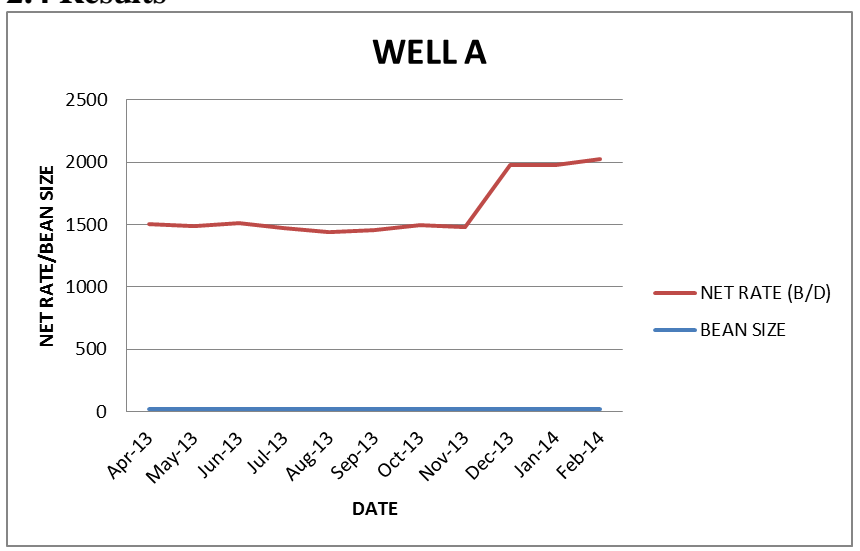

Figure 1: Production Performance Plot for Well A

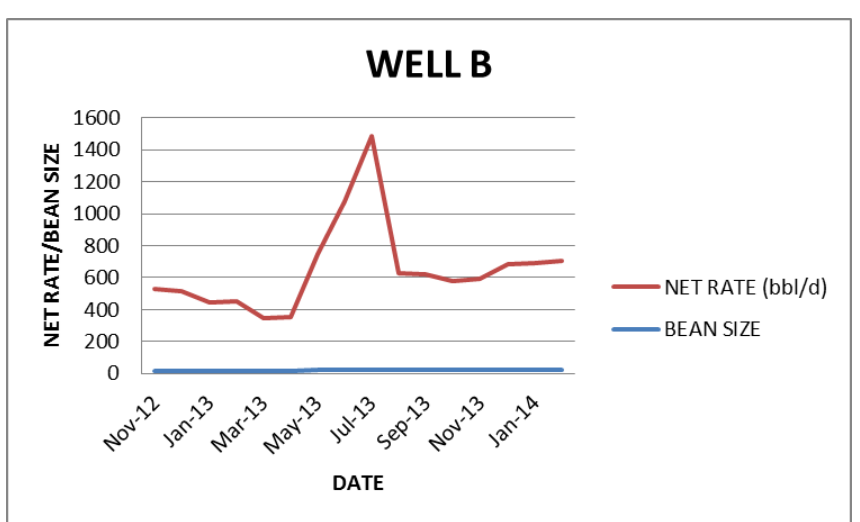

Figure 2: Production Performance Plot for Well B 


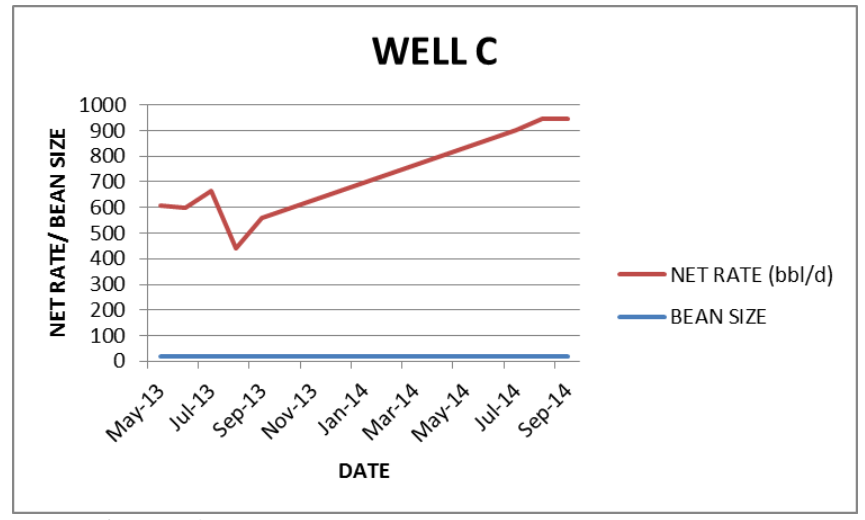

Figure 3: Production Performance Plot for Well C

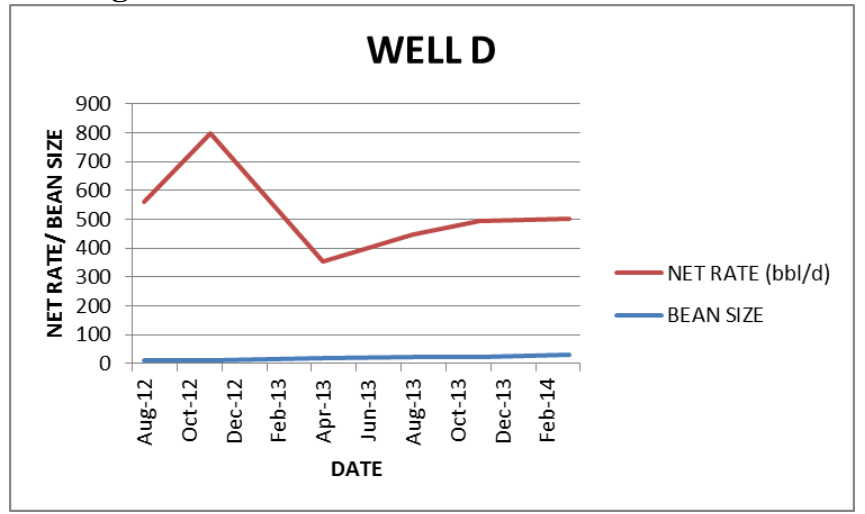

Figure 4: Production Performance Plot for Well D

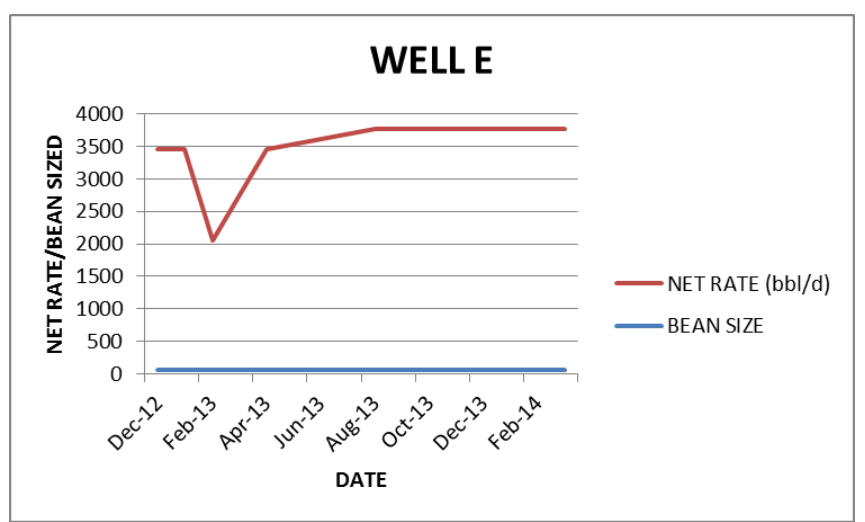

Figure 5: Production Performance Plot for Well E

\subsection{Discussions}

The results of the job evaluation parameters for wells studied are summarized in table 6 below. From the job evaluation parameters presented in the table, it could be found that the success of the treatment in the wells studied decreases in the order: $\mathrm{E}>\mathrm{C}>\mathrm{D}>\mathrm{A}>\mathrm{B}$. wells $\mathrm{C}, \mathrm{D}$ and $\mathrm{E}$ were able to achieve production rates greater than the prejob rates after treatments, evident by their stimulation ratios being greater than one (>1), while wells $\mathrm{A}$ and $\mathrm{B}$ shows no gain in production after treatment.
Table 6: Results Summary of the Job Evaluation Parameters for Wells A-E

\begin{tabular}{|l|l|l|l|l|}
\hline \multirow{2}{*}{$\begin{array}{l}\text { Well } \\
\text { Name }\end{array}$} & \multirow{2}{*}{ Stimulation } & \multicolumn{2}{|l|}{ Stimulation Ratio } & Skin \\
& & $\begin{array}{l}\text { From } \\
\text { RI }\end{array}$ & $\begin{array}{l}\text { From } \\
\text { Rates }\end{array}$ & \\
\hline A & 0.00 & 1.80 & 0.95 & 66.00 \\
\hline B & 0.00 & 1.60 & 0.77 & 56.70 \\
\hline C & 387.00 & 3.80 & 1.72 & 97.90 \\
\hline D & 85.00 & 2.90 & 1.25 & 79.50 \\
\hline E & 1713.00 & 5.10 & 1.90 & 100.00 \\
\hline
\end{tabular}

Poor results obtained in sandstone acid treatment sometimes may be caused by factors which include:

1. Use of inadequate mud acid volume which results to incomplete removal of damage leading to treatment failures.

2. Lack of hydrochloric acid pre-flush.

3. Lack of immediate cleanup after treatment.

4. Fracturing the formation during treatment.

5. Lack of use of mutual solvent with mud acid treatment.

6. Use of diesel oil as after flush in gas and water injection wells.

In order to improve the success of the acidizing jobs in oil producing wells, the following steps proposed based on the study of the analytical data can ensure an effective job. They include:

I. Performing precise pre-job test/analysis for proper candidate selection before job execution.

II. Ensuring great accuracy in job designing with emphasis on accuracy in specific volumes and types of fluid to be injected into the formation as well as maximum possible injection rate and treatment pressure in order not to fracture the formation.

Other includes:

i. Quality treatment fluid preparation.

ii. Pre-job equipment preparation/testing.

iii. Holding pre-job meeting before execution of jobs to ensure that every on site is aware of the job execution procedure.

iv. Application of a hydrochloric acid pre-flush

v. Finally ensuring an adequate recovery of acid spent by placing the well on production immediately after treatment except in clay acid treatment, which requires a shut in period for the clay stabilization process to work

\section{CONCLUSION}

In an attempt to achieve the objective of this study, discussions have been centered on the fundamentals of formation damage and acidizing, review of existing literature on the subject and matrix models, research methodology, analysis of data and discussion of results.

From the results obtained, the following conclusions were made:

1. In successful treated wells studied, stimulation ratios from productivity indices were almost equal to or greater than $2(\geq 2)$ and always greater than stimulations ratios from production rates, showing that the treatments were positive in reducing or curing 
damage around the wellbore but the stimulation ratios from the two parameters (productivity index and production rate) were not the same as a result of flow restrictions probably due to migration of fines, chemical deposition, reservoir condition and mechanical factors.

2. While all wells showed positive response to reduction of damage as shown by estimated proportion of initially existing damage removal by each treatment, only three wells (C, D and E) showed positive results in achieving production above their pre-job rates immediately after treatment.

3. Since all treated intervals in different wells studied showed positive response to damage reduction, it could be concluded that acidizing if properly executed will reduce or cure damage around the wellbore and probably improve productivity.

\subsection{Recommendation}

In order to improve the performance of acidizing operations, the following recommendations have been made:

1. Acidizing operations should be limited to wells having adequate reserves remaining in the reservoir where economic gain is sure to be made.

2. Since treatment fluids follows the path of least resistance, resulting to all of the treating fluid entering only a relatively small section of the intended treatment zone, the use of an effective method of diversion is therefore recommended. This could be achieved by either mechanical means (use of packers, ball sealer, coil tubing, etc.) or chemical means (use of oil soluble resins, bridging agents, foams). In foam diversion, it is not recommended to add any type of gelling agent to the base foam fluid, as this could cause damage to the formation.

3. As some clay and feldspar type materials may react with HCL to provide mobile fines, the HCL concentration should be decreased when treating formations that are known to contain fines. Although the HCL pre-flush is used to dissolve carbonates within the formation, when treating sandstones that has no carbonates, a small pre-flush is nevertheless recommended prior to the HCL-HF treating fluids. This is required to prevent any precipitation that may occur should the mud contact the formation water.

4. Mud acid must only be prepared using fresh water as calcium and magnesium carbonates plus sodium and potassium brines will react with $\mathrm{HF}$ to form soluble precipitates. Consequently, seawater must not be used in the preparation of acid system.

5. When stimulating a well that has been consolidated, it is strongly recommended that the acid strength be reduced since despite the fact that resin used are acid resistant, some degradation can be caused by full strength mud acid.

6. In the event that during any job execution, there is equipment failure and the acid cannot be recovered, it should be over displaced a minimum distance of about $5 \mathrm{ft}$ into the formation. This technique can also be applied to large volume jobs that have been designated to be shut-in overnight

\section{REFERENCES}

[1]. Boyungwo, William C. L and A. Ghalambor (Feb, 2007), Petroleum Production Engineering: A Computer Assisted Approach, Elsevier Science and Technology

Books, Lafayette. P. $224-252$.

[2]. Chia, Adu and Olobi (1989), "Utorogu Gas Well Stimulation: A Quantitative Approach towards Improving Well Performance", Paper SPENC 8905 presented at the $13^{\text {th }}$ annual international conference of SPE Nigeria council, P. $60-72$.

[3]. Crowe, C. W (1991), "Evaluation of Oil Soluble Resin Mixtures as Diverting Agents for Matrix Acidizing", SPE $3505,46^{\text {th }}$ annual meeting SPE-AIME, new Orleans.

[4]. Ellenberger, C. W and Aseltine, R.J (1977), "Selective Acid Stimulation to Improve Vertical Efficiency in Injection Wells: A Case History:, JPT. Vol. 213, No. 5, P. 25 - 28.

[5]. Farley, J. T, Miller, B. M and Schoettle, W. (1970), "Design Criteria for Matrix Stimulation with Hydrochloric Hydrofluoric acid”, JPT. Vol. 97, No. 23. P. 43 - 44.

[6]. Guin, J. A and Schecter, R. S (1991), "Matrix Acidizing With Highly Reactive Acids”, SPE journal, P. 390 - 398

[7]. Jennings, A. R and Sprawls, B. T (1977), "Successful Stimulation in Cotton Valley Sandstone: A Low Permeability Reservoir", JPT. P. 67 -72

[8]. Mc Cune, C. C, Ault, J. W and Dunlop R.G, (1985), "Reservoir Properties Affecting Matrix Acid Stimulation of Sandstones", JPT. Vol. 363, No. 56, P. $63-67$.

[9]. Oribabor, O. J (1987), "Experience With Matrix Acid Stimulation in Oil Wells in SPDC - Eastern Division, Nigeria", Paper SPENC Presented at the $11^{\text {th }}$ Annual International Conference of SPE Nigeria Council.

[10]. Paccoloni, G and tambini, M (1990), "Advances in Matrix Stimulation Technology", Paper SPE 20623 Presented at the Annual Technical Conference and Exhibition, New Orleans, L. A 